LAWRENCE LIVERMORE N A T IO N A L LABORATORY
Safety Report - Experiments 999 and 891 Muon Spin Relaxation in Pu and Pu-based Heavy Fermion Materials

Michael Fluss, Robert Heffner, Gerald Morris

June 8, 2004 
This document was prepared as an account of work sponsored by an agency of the United States Government. Neither the United States Government nor the University of California nor any of their employees, makes any warranty, express or implied, or assumes any legal liability or responsibility for the accuracy, completeness, or usefulness of any information, apparatus, product, or process disclosed, or represents that its use would not infringe privately owned rights. Reference herein to any specific commercial product, process, or service by trade name, trademark, manufacturer, or otherwise, does not necessarily constitute or imply its endorsement, recommendation, or favoring by the United States Government or the University of California. The views and opinions of authors expressed herein do not necessarily state or reflect those of the United States Government or the University of California, and shall not be used for advertising or product endorsement purposes.

This work was performed under the auspices of the U.S. Department of Energy by University of California, Lawrence Livermore National Laboratory under Contract W-7405-Eng-48. 


\section{Safety Report - Experiments 999 and 891 \\ Muon Spin Relaxation in Pu and Pu-based heavy fermion materials.}

2004.3.19

\section{Contact Information}

\author{
Robert Heffner (Experiment Co-Leader) \\ Los Alamos National Laboratory \\ MST-10, MS K764 \\ Los Alamos, NM 87545 \\ USA
}

\author{
Micheal Fluss (Experiment Co-Leader) \\ Lawrence Livermore National Laboratory \\ P.O. Box 303, East Avenue \\ Mail Stop L-090 \\ Livermore, CA 94550 \\ Gerald Morris (Safety Coordinator) \\ Los Alamos National Laboratory \\ MST-10, MS K764 \\ Los Alamos, NM 87545 \\ USA
}

\author{
email: heffner@lanl.gov \\ phone: 505-667-0397 \\ fax: 505-665-7652
}

email: fluss1@1lnl.gov phone:925-423-6665

fax: 925-423-4306

email: gmorris@lanl.gov

phone: $\underline{505-667-4255}$

fax: 505-665-7652

\section{Overview}

Experiment E999 proposes to carry out conventional muon spin relaxation ( $\mu$ SR) measurements on solid samples of plutonium and plutonium alloys. Experiment 891 will be involved with $\mu \mathrm{SR}$ experiments on $\mathrm{PuCoGa}_{5}$ and related $\mathrm{Pu}$-based superconductors. Other than a dedicated cryostat to be provided by Los Alamos and a pumping station provided by Livermore, the experiments will use existing $\mu$ SR User Facility spectrometers and associated equipment such as detectors and electronics. The main topics of this report are therefore 1) the passivation of the samples with a polymer coating, 2) the design, fabrication and testing of a sealed titanium sample secondary encapsulation cell, 3) the transport of samples to and from TRIUMF and 4) the related on-site procedures for the safe handling of the encapsulated samples. Because both E999 and E891 share the same equipment and Pu-safety related issues, we are submitting a single safety report for both experiments.

\section{General}

No abnormal hazards associated with the $\mu$ SR spectrometer itself are being introduced. Hazards routinely encountered in a $\mu$ SR experiment include liquid nitrogen and liquid helium used in cryostats and superconducting magnets, high current magnet power-supplies, and high voltage $(<3 \mathrm{kV})$ detector power-supplies. Very strong magnetic fields are used in the course of carrying out the experiment. Normal precautions regarding the use of cryogens, high current magnet power supplies, high voltage detector power supplies, and working near strong magnetic fields will be observed. Magnet 
power supplies and high voltage power supplies will be locked out or otherwise disabled before making or breaking connections. Magnetic objects such as tools will be removed from the vicinity of spectrometer magnets before they are energized. Except for the $\mathrm{Pu}$ materials being studied, these experiments use a conventional $\mu$ SR setup using largely TRIUMF Facility equipment. We will provide a helium flow cryostat fully compatible and identical in operation to existing Facility equipment and a high vacuum pumping station to avoid possible negative impact on Facility equipment in the unlikely event of radiological contamination.

\section{LLNL and LANL Integrated Work Statements}

Integrated Work Statement (IWS) documents will be developed and approved at LLNL and LANL for the preparation of the encapsulated sample(s), and subsequent packing and shipping of Pu samples to TRIUMF. The LLNL document is attached to this report as Appendix A. The LANL document for the preparation of the encapsulated sample(s), and subsequent packing and shipping of Pu samples to TRIUMF will be similar to LLNL's and is in preparation. A written acceptance of the proposed experiment, and approval by TRIUMF's Safety Review process will be required by LLNL/LANL prior to shipment of the samples from LLNL/LANL to TRIUMF.

\section{Sample Hazards}

Plutonium is an alpha emitter and poses (primarily) a radiological hazard. Our objective in designing sample containment is to be confident that no $\mathrm{Pu}$ will be released into the laboratory environment, the interior of the cryostat during experiments, nor into the shipping container during shipping and handling prior to, during, and after these experiments. No more than two samples for each experiment will be on-site at TRIUMF at any given time.

Each sample for E999 will contain less than $0.25 \mathrm{~g}$ of ${ }^{239} \mathrm{Pu}$ which has a half life of 24,110 years. This implies a maximum activity of $0.58 \times 10^{9} \mathrm{~Bq}$. However, actual activity will depend on the $\mathrm{Pu}$ isotopes and the age of the sample due to parent-daughter growth of ${ }^{241} \mathrm{Am}$ (see Tables I and II). The actual alpha and gamma dose will be measured for all samples and/or determined from isotopics of the Pu assay at LLNL at each step of the encapsulation procedure (an estimate of the gamma dose for the double encapsulated sample is shown in Table II). Secondary encapsulation materials will stop all alphas thus significantly reducing the ionizing radiation hazard and leaving a gamma hazard dominated by radiation below $15 \mathrm{keV}$.

Each sample for E891 will contain less than $0.5 \mathrm{~g}$ of ${ }^{239} \mathrm{Pu}$ in the form of compounds like PuCoGa5. The numbers discussed above for E999 can be scaled accordingly.

\section{Sample Containment}

The $\mathrm{Pu}$ or $\mathrm{Pu}$-alloy samples will be in the form of a thin polycrystalline metallic foil 10 to $15 \mathrm{~mm}$ in diameter. The $\mathrm{PuCoGa}_{5}$ will be in the form of a plate-like single crystal. Under experimental operating conditions the sample will have two levels of containment. These two independent and different methods will be used to contain the sample material thus avoiding a single point failure scenario. A screw-on cover, in 
addition to the shipping packaging, will be provided that is mechanically robust so as to protect the entire sample assembly during shipping (see Fig .1).

\section{Polyimide encapsulation (primary encapsulation)}

The practical risk faced by experimenters and technical personnel is inhaling or ingestion of $\mathrm{Pu}$ contamination due to either $\mathrm{Pu}$ dispersal from recoil processes involving the energetic particle emission or from $\mathrm{Pu}$ dispersion resulting from the friability due to oxidation.

We have developed and employed in the past a containment, encapsulation, and passivation procedure to deal effectively with these risks by using polyimide. At LLNL/LANL $\mathrm{Pu}$ samples will be shaped, thinned, and have surface oxide removed inside a glove box that has oxygen and water vapor at ppm levels. The Pu sample will be sealed in a polyimide (Kapton) coating. Each sample will be encapsulated in an $10-20$ $\mu \mathrm{m}$ thick polyimide film. The film is applied as a viscous liquid that is cured at elevated temperature. The coated sample will then be attached with GE Varnish to and then enclosed inside a titanium cell shown in Fig. 1. We note that encapsulation with a polyimide coating provides the following properties:

- The short range $(\sim 50 \AA$ in polyimide) of the $\mathrm{U}$ or $\mathrm{Pu}(<86 \mathrm{keV})$ recoils means that one micron of polyimide is sufficient to contain all spall and ejecta. This assures that the sample holder is left uncontaminated. Experience at LLNL has shown such a coating to inhibit oxidation of the Pu thus limiting friability. Encapsulated samples in high vacuum have resulted in no detectable loose $\mathrm{Pu}$ activity for periods as long as one year. By no means does such a thin coating reduce the radiation hazard from alpha particles and $\gamma$-rays emitted by the sample which penetrate the polymer coating, but $\mathrm{Pu}$ material containment is assured and the potential for dispersal is made negligible.

- The temperature of the curing process of the coated samples establishes a safe operational maximum temperature. Polyimide is a proven method of containing $\mathrm{Pu}$ from cryogenic temperatures up to $\sim 600 \mathrm{~K}$. It is very tough, resistant to abrasion and peeling. This is an excellent primary passivation method should the the secondary encapsulation fail.

The integrity of the polyimide-encapsulated sample will be assured by radiological swipe tests. Only coated samples free of removable radioactive surface contamination will be used.

\section{Titanium sample cell (secondary encapsulation)}

We have designed and tested a sealed titanium sample cell for these experiments. A Ti window will act as a second encapsulation, while a robust third containment for the shipping and handling of the Pu sample is also employed. Details of the cell assembly are shown in Fig. 1.

The cell base plate, window assembly and screws are made of (non-magnetic) titanium, assuring uniform thermal properties. A gold wire gasket compressed between the plate and window assembly provides a gas-tight seal. A thin window is necessary to allow the $4.2 \mathrm{MeV}$ surface muon beam into the cell. This window is a $0.05 \mathrm{~mm}(0.002$ inch) thick $\mathrm{Ti}(6 \% \mathrm{Al}-4 \% \mathrm{~V})$ alloy foil, electron-beam welded to the Ti body of the cell. This window is designed according to the Fermi Lab design note FNAL-TM-1380 "Mechanical Safety Subcommittee Guideline for Design of Thin Windows for Vacuum 
Vessels", which is attached to this safety report as Appendix B. Burst pressure of this window is expected to exceed 74 psi ( 5 atmospheres).

The Ti body, base plate and gold gasket are assembled under 1 atm of helium using ten \#4-40 titanium screws tightened to 10 in.-lbs. (A pure indium gasket would be superconducting below $3.4 \mathrm{~K}$ ). While inside the evacuated cryostat the pressure differential across the window will be 1 atmosphere or less, depending of temperature. Samples will not be raised to temperatures above ambient while at TRIUMF.

The very substantial screw-on cover is designed to protect the foil window from accidental puncture during shipping and handling. This $5 \mathrm{~mm}$ thick stainless steel cover will also serve to minimize gamma-ray exposure while the sample cell is being handled and mounted onto the cryostat.

The interior surfaces of the Ti cell will remain free of $\mathrm{Pu}$ or $\mathrm{U}$ recoils. Using both a polyimide film and a Ti window gives us two different containment techniques which eliminates any chance of a failure common to both. This encapsulation scheme is preferable to a doubled-windowed cell because limiting the design to only one Ti window

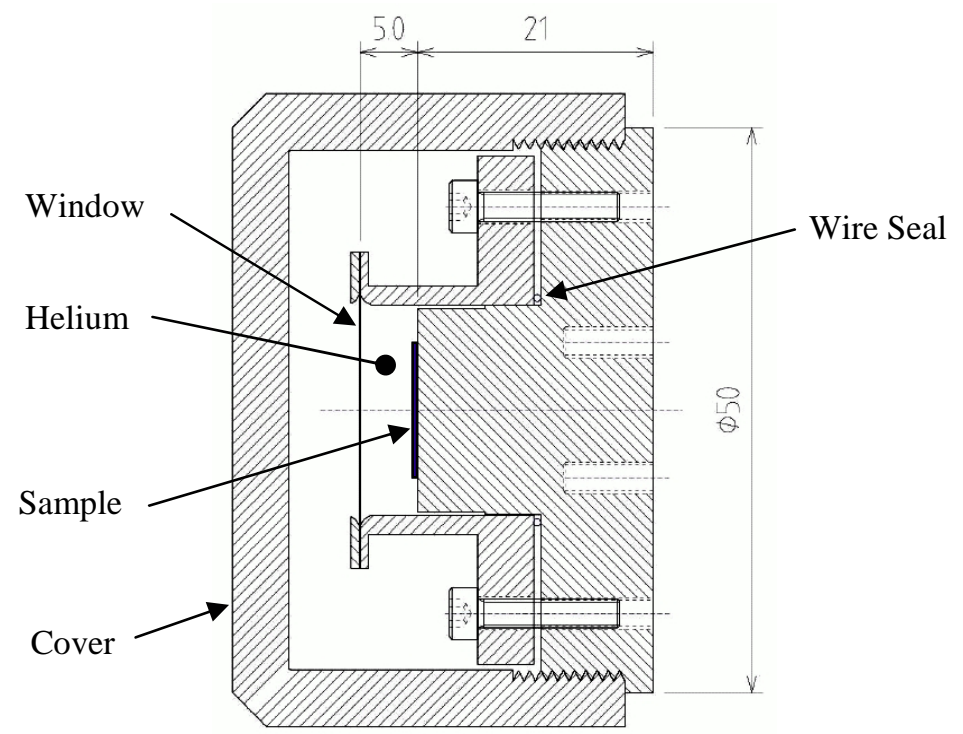

Fig. 1. A cross-sectional view of the titanium sample cell shown with the protective cover installed. Dimensions are in $\mathrm{mm}$.

Muons enter the cell window from the left.

decreases the beam spot diameter by allowing a more compact geometry while scattering of muons in a thin coating in direct contact with the sample will have no effect on the beam spot size. This will result in better data with little (or no) background signal from the Ti cell.

A prototype cell has been constructed and subjected to repeated vacuum cycling at room temperature inside a test chamber over a period of 5 days with no evidence of degradation of the window or gold wire seal. It has also been thermally cycled from room temperature down to about $16 \mathrm{~K}$ and back to room temperature twice over a period of two days (with the same gold gasket, untouched) while the test chamber was pumped with a helium leak detector. No leaks of the enclosed helium were found at any time during these tests.

If required the loaded sample cells can be checked for helium leakage on site at 
TRIUMF before insertion into the beam line.

Fig. 2. Proposed design of the CryoIndustries cold finger cryostat.

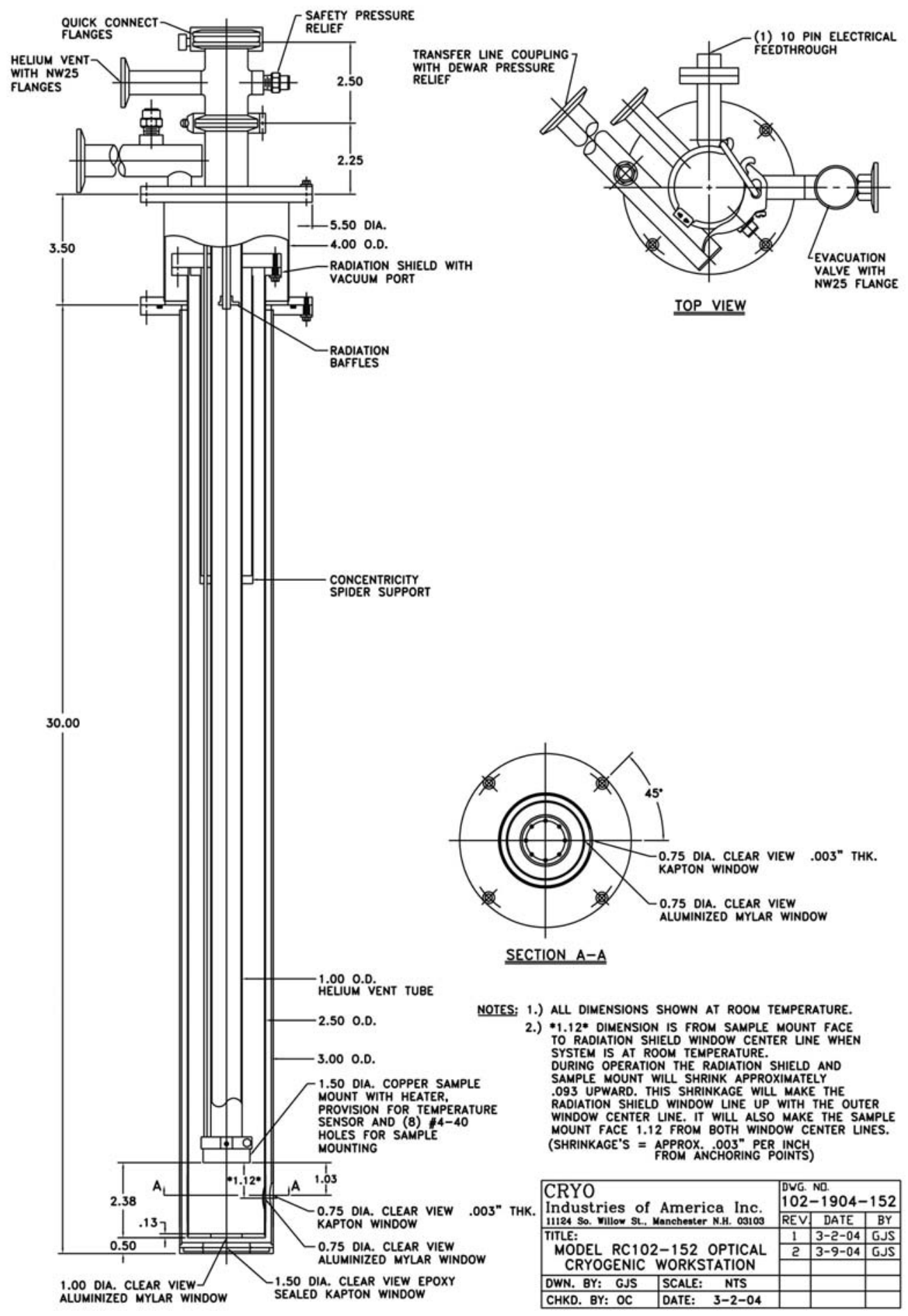




\section{Cryostat}

We will provide a CryoIndustries RC102 cold-finger cryostat similar to existing TRIUMF $\mu$ SR facility cryostats in design and operation (Fig. 2). Liquid helium is delivered to the cryostat by a continuous-flow transfer line from a liquid-He storage dewar. The sample cell is always in high vacuum and does not come into contact with the helium cryogen. Muons will enter the cryostat through a 0.003 inch Kapton beam window in the vacuum shroud. The cryostat will be equipped with two calibrated Lakeshore GaAlAs diode thermometers to be inserted into mounting holes in the sample cell baseplate, close behind the sample, and a heater for controlling sample temperature. Facility temperature controllers will be compatible with the cryostat thermometers and heater.

\section{Cryostat Vacuum Exhaust}

The cryostat vacuum space is to be pumped with a turbo pumping station, the exhaust of which is to be released through a filter into a vent line in the M20 area equipped with radiation monitoring equipment appropriate for low levels of $\mathrm{Pu}$ contamination. TRIUMF is asked to design and install any new lines and equipment which are required to complete this vent line; we will provide the pumping station and inline filter.

\section{Spectrometer}

The cryostat is designed to be compatible with Helios (axial) or Omni and LAMPF (axial and side access) spectrometers. The cryostat will be secured to the spectrometer with a Facility-provided mount which allows adjustments for alignment. All other equipment such as helium pumps, detectors, temperature controllers and DAQ systems are existing items to be provided by TRIUMF.

\section{Sample mounting and de-mounting}

Sealed sample cells as shown in Fig. 1 will be prepared at LLNL and LANL and transported by ground, or ground-air-ground to TRIUMF in approved containers which meet US and Canadian transport regulations. During transportation and all handling, the Ti cell window will be protected by a screw-on cover which is secured to the thick baseplate of the Ti cell.

Unpacking and mounting of sample cells onto the cryostat cold-finger will be done in a radiation work area approved for this activity by TRIUMF Safety Group. The cryostat will be removed from the spectrometer and taken to the radiological work area for sample cell mounting. Handling of the cell to secure it to the cryostat will proceed as follows.

On removal of a sample cell from its shipping container, a TSG technician will perform a swipe test for removable contamination. The cell beam window will be protected with the cover which would be removed for the swipe and re-installed. Installation of the cell on the cryostat will be completed before the protective cover is removed again. Last, the cryostat heat shield and vacuum shroud would then be installed over the cell and cold finger.

The closed cryostat will be transferred to the experimental area and mounted onto the spectrometer. The pumping station will be reconnected to the cryostat and the isolation valve to the cryostat pumping port slowly re-opened (so as not to create viscous 
flow which could shift loose contamination if it were present.) The helium supply and exhaust lines and thermometry cables will be connected. At this stage the experiment is ready to run.

Removal of the sample from the cryostat will proceed as follows: The cryostat will be warmed to room temperature, then disconnected from He supply and exhaust lines and thermometer and heater cables. The vacuum shroud will be isolated from the pump by closing the pumping port valve. A "hot break" (in which the connection to be opened is bagged and surveyed) is made between the vacuum pump and isolation valve. The cryostat is then withdrawn from the spectrometer magnet and transferred to the radiation work area for disassembly. Venting the vacuum space of the cryostat will be done slowly to avoid viscous flow. The vacuum shroud would be opened several $\mathrm{cm}$, far enough to allow a swipe to be taken from the inside of the cryostat and re-closed while the swipe is assayed. The cryostat would be re-opened if no contamination is found. The vacuum shroud and heat shield is then removed and the Ti window is covered with the screw-on cap. A swipe of exposed surfaces of the cell and cryostat parts is then to be taken to determine the state of any contamination. The screws holding the cell to the cold finger are then removed and the cell is detached and put into its shipping container. The shipping container may then to be moved to a storage location designated by TRIUMF (which might be within the radiological work room.)

\section{Doses}

The isotopic composition of a typical metallic $\mathrm{Pu}$ sample is shown in Table I.

Table II shows the calculated dose rates through the Ti window, the back and the side of the sample holder with and without the tertiary cover in place. Dose rates at the front window surface $(1.5 \mathrm{~cm})$ and at further distances are indicated for a $250 \mathrm{mg}$ sample with typical $\mathrm{Pu}$ isotopes and for various ages to account for decay products.

\begin{tabular}{|l|c|c|}
\hline \multicolumn{1}{|c|}{ Isotope } & Amount & $\begin{array}{c}\text { Minimum Detectable } \\
\text { Limit }\end{array}$ \\
\hline${ }^{234} \mathrm{U}$ & $0.001(2)$ at. $\%$ & 0.01 at. $\%$ \\
\hline${ }^{235} \mathrm{U}$ & $7(6)$ at. ppm & 10 at. ppm \\
\hline${ }^{237} \mathrm{~Np}$ & $24(7)$ at. $\mathrm{ppm}$ & 5 at. ppm \\
\hline${ }^{238} \mathrm{Pu},{ }^{238} \mathrm{U}$ & $0.17(2)$ at. $\%$ & 0.05 at. $\%$ \\
\hline${ }^{239} \mathrm{Pu}$ & $93.7(1)$ at. $\%$ & 0.2 at. $\%$ \\
\hline${ }^{240} \mathrm{Pu}$ & $5.86(5)$ at. $\%$ & 0.02 at. $\%$ \\
\hline${ }^{241} \mathrm{Pu},{ }^{241} \mathrm{~A}$ & $0.200(5)$ at. $\%$ & 0.001 at. $\%$ \\
\hline${ }^{242} \mathrm{Pu}$ & $0.045(2)$ at. $\%$ & 0.0002 at. $\%$ \\
\hline
\end{tabular}

Table 1. Isotopic composition of a typical metallic $\mathrm{Pu}$ sample. 
The principle exposure while handling and installing/removing the sample cell in the cryostat will be low energy gamma rays, about $99.6 \%$ of which are below $15 \mathrm{keV}$.

Exposure of experimenters to gamma radiation will be kept to a minimum by maximizing distance and minimizing exposure time. Alpha particles $(5 \mathrm{MeV})$ from $\mathrm{Pu}$ or $\mathrm{U}$ decay will be stopped by the Ti foil window. Recoil $\mathrm{U}$ and $\mathrm{Pu}$ atoms produced in the $\mathrm{Pu}$ decay will be stopped by the polyimide film. Suitable hand dosimetry should be provided by TRIUMF Safety Group. The integrity of the polyimide and Ti window cell assure no inhalation or digestion of $\mathrm{Pu}$ particles.

The muon beam, decay positrons and $0.511 \mathrm{MeV}$ annihilation gamma-rays produce a negligible dose to experimenters.

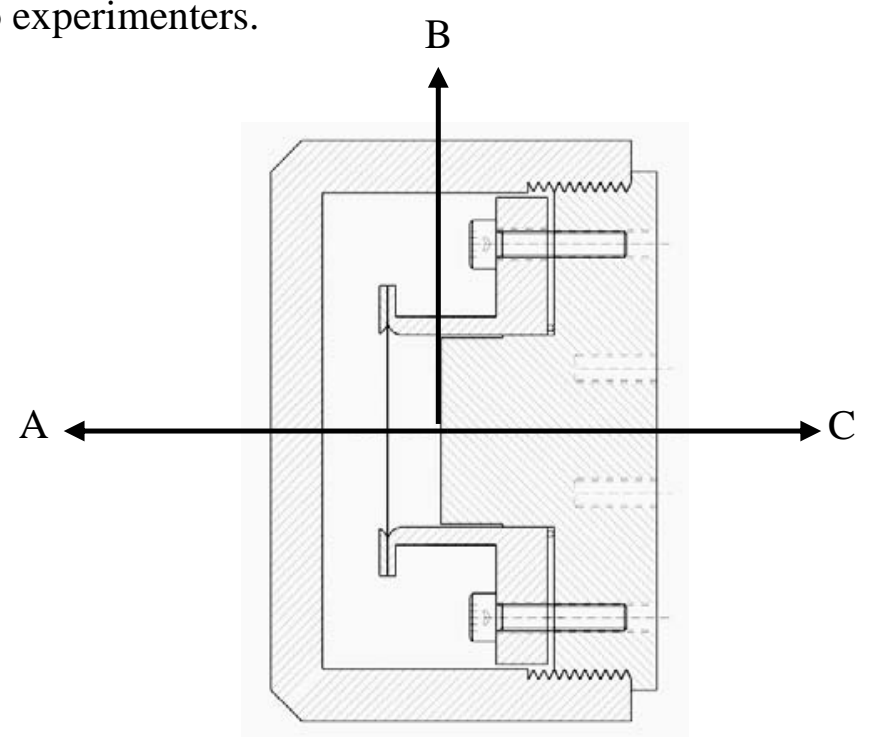

Table II: Estimated dose rates in $\mathrm{mR} / \mathrm{hr}$ at various distances from the sample along lines $\mathrm{A}, \mathrm{B}$ and $\mathrm{C}$ with and without the stainless steel cover present, assuming the sample to be a point source.

\begin{tabular}{|l|l|l|l|}
\hline Direction & Distance $(\mathrm{cm})$ & Cover Present & Cover not present \\
\hline A & 0.55 & & $1.34 \times 10^{6}$ \\
\hline & 1 & & $3.43 \times 10^{5}$ \\
\hline & 1.6 & 162 & \\
\hline & 5 & 16.6 & $1.36 \times 10^{4}$ \\
\hline B & 30 & 0.46 & 361 \\
\hline & 1.2 & & 462 \\
\hline & 2.8 & 51.4 & \\
\hline & 5 & & 26 \\
\hline & 5.7 & 12.35 & \\
\hline C & 30 & 0.45 & 0.74 \\
\hline & 2.2 & & 70.3 \\
\hline & 5.0 & & 13.6 \\
\hline & 30 & & 0.38 \\
\hline
\end{tabular}




\section{Hazards Analyses and Controls}

The experiments at TRIUMF involve the investigation of actinides at room temperature and below. Potential for exposure to the sample material exists if the integrity of the polymer coating and Ti cell are simultaneously compromised. Two different sample encapsulation schemes are to be used, either of which is designed to be sufficient to contain all the sample material should the other fail. The polyimide coating is known to reliably contain all sample material, excepting alpha and gamma radiation. The titanium cell serves to protect the polyimide-encapsulated sample, provides a secondary encapsulation, stops all alphas and, with the cover installed, greatly reduces exposure to gammas during handing.

Residual vacuum gases from the space containing the sample cell are vented to air outside the building via a monitored and filtered vent line. A filter after the pumping station serves to collect particles in a well-defined volume making detection of radioactivity easier, if it is present at all. In the unlikely event sample material is released into the cryostat vacuum space, it will not be released into the building environment.

Potential hazards in carrying out these experiments are also posed by the use of liquid helium and nitrogen cryogens, high voltage power for particle detectors and high current magnet power supplies. Cryogens can cause burns to exposed parts of the body. If liquid helium or nitrogen leaks or vents into a small or enclosed space, an oxygen deficiency may result. We note that the open nature of the experimental areas at TRIUMF mitigates the potential for oxygen exclusion, even in the event of a superconducting magnet quench. Electrical hazards are to be controlled by the use of standard industrial practices and approved equipment in good condition. High voltage and high current power supplies will be turned off, disabled and/or locked out before making or breaking connections.

LLNL and LANL require the following administrative controls

- $\quad$ All LLNL \& LANL personnel working at offsite locations must follow all applicable local safety procedures and take any required facility specific safety training before performing their experimental work.

- All on and off site transportation of these samples will meet LLNL/LANL Materials Management Section requirements. Specifically, offsite transportation will be conducted in a manner that meets all applicable Department of Transportation (US-DOT) regulations.

- Safety concerns about these facilities should first be discussed with local facility safety staff. Unresolved safety concerns may also be discussed with the LLNL and LANL ES\&H Team staff.

- If used, dosimeters should be provided by the facility being visited. Radiation safety and survey equipment and personnel will be provided by the local facility.

- $\quad$ The use of liquid cryogens and the resultant possibility of an oxygen deficiency will be discussed and resolved with local facility safety staff.

TRIUMF is required to provide to LLNL and LANL written assurance that safety approval is given and that TRIUMF is prepared to receive the samples. 


\section{On-site TRIUMF Procedures}

Experimenters performing work involving the sample cells and cryostat will conform to TRIUMF safety requirements. All handling, installation and removal of the sample cells will be carried out in a radiological work area under TSG supervision. Repackaging of the samples for shipment back to LLNL/LANL is to be performed by TSG.

\section{Shipping and Storage}

TRIUMF Safety Group and LLNL/LANL S\&H will specify a suitable container, likely Type A, for shipping samples to and from TRIUMF. Type A containers meeting current IAEA regulations are approved by both U.S. and Canadian regulations for shipping via ground transportation. It is essential that personnel responsible for shipping and receiving radioactive materials at TRIUMF and LLNL/LANL collaborate to establish a shipping protocol to and from TRIUMF well in advance of the experiment, including identifying appropriate carriers.

TRIUMF will be required to provide appropriate on-site short-term storage for the samples and shipping containers.

\section{Decommissioning}

Samples (and any $\mathrm{Pu}$-contaminated equipment) will be returned to their point of origin in the US after each running period and at the conclusion of the experiment. All radioactive materials should be packaged by TSG to ensure the shipment meets transport requirements.

\section{Appendix A}

LLNL/LANL Integrated Work Statements (ISW) not yet attached.

\section{Appendix B}

Design note FNAL-TM-1380 "Mechanical Safety Subcommittee Guideline for Design of Thin Windows for Vacuum Vessels" is attached. 